\title{
Psychometric Properties of the Reynolds Child Depression Scale in Community and Clinical Samples
}

\author{
Anna Figueras Masip ${ }^{1}$, Juan Antonio Amador Campos², and Joan Guàrdia Olmos ${ }^{2}$ \\ ${ }^{1}$ Departament d'Innovació, Universitats i Empresa, Generalitat de Catalunya (Spain) \\ ${ }^{2}$ Universitat de Barcelona (Spain)
}

\begin{abstract}
The factor structure of the Reynolds Child Depression Scale (RCDS; Reynolds, 1989), analyzed by confirmatory factor analysis and the scale's psychometric characteristics in a sample of 315 participants (140 boys and 175 girls) and a clinical sample of 62 participants ( 37 boys and 25 girls) between 10 and 12 years old, are presented. Two models are tested with confirmatory factor analysis: a one-factor model and a five-factor model. Both models show a good fit, but the one-factor model was chosen because it is the most parsimonious. The reliability coefficient ranged from .87 (at test) to .89 (at retest) in the community sample, and was .90 in the clinical sample (at test). Test-retest reliability was .66 in the community sample. Concurrent validity with other self-reports that measure depressive symptomatology was high, both in the community sample (.76) and the clinical sample (.71). There were no significant sex differences but there were differences due to age (school grade).

Keywords: depressive symptoms, childhood, assessment, self-report, RCDS, confirmatory factor analysis
\end{abstract}

\begin{abstract}
Se analiza la estructura factorial de la Reynolds Children Depression Scale (RCDS; Reynolds, 1989) mediante análisis factorial confirmatorio y se presentan sus características psicométricas en una muestra comunitaria de 315 participantes ( 140 chicos y 175 chicas) y en una muestra clínica de 62 participantes (37 chicos y 25 chicas) con edades comprendidas entre los 10 y los 12 años. En el análisis factorial confirmatorio se prueban dos modelos, uno unifactorial y otro de cinco factores. El modelo unifactorial se ajusta mejor y es más parsimonioso. La fiabilidad de la RCDS es elevada para ambas muestras: consistencia interna entre 0,87 (test) y 0,89 (retest) en muestra comunitaria, y de 0,90 en la muestra clínica (test); la correlación test-retest era de 0,66 en la muestra comunitaria. La validez concurrente con otros instrumentos que miden sintomatología depresiva era elevada, tanto en muestra comunitaria $(0,76)$ como en muestra clínica $(0,71)$. No se aprecian diferencias según sexo, pero sí según el curso escolar.

Palabras clave: síntomas depresivos, niñez, evaluación, autoinforme, RCDS, análisis

factorial confirmatorio
\end{abstract}

This work was partly supported by grant SEJ2005-09144-C02-01/PSIC from the Ministerio de Educación y Ciencia and by grant 2005SGR 00365 from the Generalitat de Catalunya,.

Correspondence concerning this article should be addressed to Juan Antonio Amador Campos, Departament de Personalitat, Avaluació i Tractament Psicològic, Facultat de Psicologia, Universitat de Barcelona, Passeig de la Vall d'Hebron, 171, 08035 Barcelona (Spain).

E-mail: jamador@ub.edu Translation: Virginia Navascués Howard

How to cite the authors of this article: Figueras Massip, A., Amador Campos, J.A. and Guàrdia Olmos, J. 
Depression in children and adolescents is an insidious disorder, often poorly identified or else considered a normal mood variation. The causes are diverse and, among others, include the type of symptomatology, the frequently covert nature of the symptoms, the consideration of the end of childhood and the beginning of adolescence as a period of changes and emotional alterations, the scarce communication between some adolescents and their parents or reference adults, and the lack of self-referral to professionals.

The symptoms considered typical of the depressive disorder in childhood and adolescence have changed over time. Del Barrio (1990) carried out a review of the works on childhood depression between 1945 and 1987 and elaborated a list with almost 40 symptoms. Of this extensive list, Del Barrio underlines that the main symptoms of childhood depression are: low self-esteem, changes in sleep pattern, loss or increase of appetite and weight, social isolation, hyperactivity, dysphoria, and suicidal ideation. These symptoms, mainly of an internal nature, are similar to those described in depression in adults. However, in childhood and adolescent depression, there are specific symptoms, such as behavior problems, irritability, temper tantrums or disobedience. As of 6 years of age, depressive symptoms in children become more similar to those of adults but, as a differential characteristic, depressive symptomatology is associated with behavior problems (Shaffi \& Shaffi, 1992).

In the last few years, considerable effort has been made to design and improve the assessment instruments of affective disorders in children and adolescents. A broad array of instruments has been created that go from self-report measurements to structured interviews, and include observation methods and parents', teachers', or peers' heteroreports (Jané, Araneda, Valero, \& Domènech, 2000; Kazdin, 1981; Kazdin \& Petti, 1982).

Pencil-and-paper self-reports provide information about the frequency and intensity of depressive symptoms. Although they are not diagnostic instruments, they are necessary in the assessment process and are very important when appraising treatment efficacy and at follow-up (Klein, Dougherty, \& Olino, 2005; Mash \& Hunsley, 2005; Orvaschel, 2004). The following self-reports assess childhood depression and have been adapted to our context: the Children's Depression Inventory (CDI; Kovacs, 1992; Spanish adaptation by del Barrio \& Carrasco, 2004) and the Children's Depression Scale (CDS; Tischer \& Lang, 1978; Spanish adaptation of TEA, 1983). In addition to these instruments, two of the most frequently used scales to assess depressive symptomatology in childhood and adolescence in the English language are the Reynolds Adolescent Depression Scale (RADS; Reynolds, 1987, 2002) and the Reynolds Child Depression Scale (RCDS; Reynolds, 1989). The scale items are short and direct, which facilitates reading and responding. Del Barrio, Colondrón, De Pablo, and Roa (1996) studied and adapted the RCDS and the RADS to Spanish.
The RCDS (Reynolds, 1989) is a short and easily administered self-report measure, designed to assess depressive symptomatology in children between the ages of 8 and 12 years. The RCDS does not provide a formal diagnosis of depression, according to the diagnostic criteria established by categorical systems such as the Diagnostic and Statistical Manual of Mental Disorders (DSM-IV-TR; American Psychiatric Association, 2000) or the International Classification of Diseases (ICD-10; World Health Organization, 1992), but it was designed to assess depressive symptomatology and to be used as a screening instrument to identify depressive symptoms at school or in clinical settings.

Mean RCDS scores in English-speaking community samples ranged between 49.00 (Baker \& Reynolds, 1988) and 66.54 (Reynolds, Anderson, \& Bartell, 1985). For the Spanish-speaking community samples, mean total scores ranged between 47.20 (Del Barrio et al., 1996) and 49.72 (López, 1985). In English-speaking clinical samples, mean total scores ranged between 53.03 (Rawson \& Tabb, 1993) and 67.32 (Stark, Reynolds, \& Kaslow, 1987).

The cut-off point (percentile 90) established by Reynolds (1989), with an American population, is situated at a raw score of 74 (73\% sensitivity and $97 \%$ specificity) for boys and girls. In studies carried out in our context (Del Barrio et al., 1996), the cut-off point decreased to 65 (percentile 95) for both sexes.

The reliability of the RCDS, analyzed by internal consistency, ranges between .85 and .90 for the standardization sample. Test-retest reliability is .82 at two weeks, and .85 at four weeks (Reynolds, 1989). Other studies report internal consistency between .79 and .90 (Bartell \& Reynolds, 1986; López, 1985; Reynolds, 1989; Reynolds et al., 1985; Stark et al., 1987), and test-retest reliability between .82 and .85 (Del Barrio et al., 1996; Reynolds \& Graves, 1989).

Concurrent validity of the RCDS has been analyzed through its correlations with other measurements of depression, anxiety, or self-esteem. The RCDS presents correlations ranging between .68 and .79 with the CDI (Bartell \& Reynolds, 1986; Kovacs, 1992; López, 1985; Reynolds, 1989; Reynolds et al., 1985); in Spanish populations, Del Barrio et al. (1996) found a correlation between the CDI and the RCDS of .73. The correlations between the RCDS and the Revised Children's Manifest Anxiety Scale (RCMAS) range between .60 and .76. The correlations with a measurement of self-esteem (Self-esteem Inventory, SEI; Coopersmith, 1981) are negative and range between -.50 and -.71 (Bartell \& Reynolds, 1986; Reynolds, 1989; Reynolds et al., 1985).

Studies of the factor structure of the RCDS are scarce. Reynolds (1989) found five factors in a community sample of 1,620 participants: dependence and concern, demoralization, externalizing symptoms and somatic complaints, depressed mood and pessimism, and anhedonia. No studies on the factor structure in Spanish population were found. 
The goal of this work is to present the factor structure of the RCDS by means of confirmatory factor analysis and the psychometric properties of the bilingual Spanish-Catalan version of the RCDS in the Catalonian children's population

\section{Method}

\section{Participants}

The community sample comprised 315 participants, aged between 10 and 12 years, from public and partially state-funded schools of the province of Barcelona, registered in $5^{\text {th }}$ and $6^{\text {th }}$ grade of Primary Education. Of the sample, $44.44 \%$ are boys (140) and $55.55 \%$ are girls (175). We contacted one school from each of the ten districts of the city of Barcelona and several schools from the province. Five schools agreed to participate in the study.

The clinical sample comprised 62 participants ( 25 girls, $40.32 \%$; 37 boys, 59.67\%), ages between 10 and 12 years. The participants were in $4^{\text {th }}, 5^{\text {th }}$, and $6^{\text {th }}$ grade of Primary Education. The clinical sample was recruited from two Children's and Youths' Mental Health Centers (in Spanish, "Centro de Salud Mental Infantil y Juvenil," hereafter abbreviated to CYMHC) of the province of Barcelona. The clinical team of the CYMHC performed the diagnosis according to the criteria of the DSM-IV-TR (APA, 2000). Of this clinical sample, 19 participants were diagnosed with depression, 21 with anxiety disorders, 9 with behavior and learning problems, and 13 had no definite diagnosis at the time of coding the RCDS data. In addition, for the study of the sensitivity and specificity of the RCDS, we selected a nonsymptomatic group from the community sample of 45 participants who scored lower than the cutoff point at the test and retest phases. This group was paired in age and sex with the group diagnosed with depression.

The socioeconomic status of the community sample, calculated with the Hollingshead (1975) index, was as follows: high $20.4 \%$, medium-high $15.1 \%$, medium $26.0 \%$, medium-low $32.2 \%$, and low $5.4 \%$. And the socioeconomic status of the clinical sample was: high $0 \%$, medium-high $12.1 \%$, medium $9.1 \%$, medium-low $66.7 \%$, and low $12.1 \%$.

\section{Instruments}

The RCDS includes 30 items, 29 of which use a 4-point Likert-type response format, ranging from 1 (almost never) to 4 (all the time). The last item of the scale presents faces with various expressions and is rated on a 5-point scale. The total score of the RCDS can range between 30 and 121 points. The RCDS can be administered individually or collectively; it can also be administered orally to children with reading difficulties. Table 1 displays the denomination proposed by Reynolds (1989) for each item.

The CDI consists of 28 items that assess depressive symptomatology. Each one of the items has three response options that score 0 (absence of symptomatology), 1 (mild symptomatology) or 2 (severe symptomatology). The total score ranges from 0 to 54 points.

The following translation and adaptation procedures were used for the RCDS and the CDI: (a) direct translation of the questionnaire from English to Spanish and from English to Catalan by two expert translators, with knowledge of psychology and psychopathology; (b) comparison of the translations to assess differences in interpretation; (c) back translation by other expert translators; (d) comparison of the direct and back-translation versions by bilingual persons to verify the conceptual and semantic equivalence of the sentences; (e) drafting the definitive version presented in this work (Brislin, 1986; Brislin, Loner, \& Thorndike, 1973; Candell \& Hulin, 1987).

The RCDS and the CDI were administered in a bilingual Spanish-Catalan version (see Annex 1). We chose this format because of our experience with previous works in which we verified that the bilingual version facilitated understanding the sentences (Abad \& Amador, 1991; Abad \& Forns, 1991a, 1991b).

Table 1

Denomination of the RCDS Items according to Reynolds (1989)

\begin{tabular}{clclcl}
\hline Item & Symptomatology & Item & Symptomatology & Item & Symptomatology \\
\hline 1 & Dysphoria & 11 & Somatic complaint & 21 & Concentration difficulty \\
2 & School anxiety & 12 & Low self-worth & 22 & Self-pity \\
3 & Loneliness & 13 & Discouragement & 23 & Reduced speech \\
4 & Devalued by parents & 14 & Self-injury & 24 & Sleep disturbance \\
5 & Self-worth & 15 & Self-esteem & 25 & Anhedonia-general \\
6 & Social withdrawal & 16 & Irritability & 26 & Worry \\
7 & Sadness & 17 & Pessimism & 27 & Somatic complaint \\
8 & Crying & 18 & Fatigue & 28 & Loss of interest \\
9 & Worthlessness & 19 & Self-reproach & 29 & Helplessness \\
10 & Anhedonia-peers & 20 & Self-deprecation & 30 & Dysphoric mood \\
\hline
\end{tabular}




\section{Procedure}

The assessment procedure followed Reynolds' (1986) multistage model. This procedure comprises three stages to identify children with depressive symptomatology. The first two phases consist of the administration of self-assessment instruments of depressive symptomatology at two different points in time with an interval of 2 or 3 weeks (test and retest phases), the minimum period established in Criterion A of the DSM-IV-TR (APA, 2000) for a major depressive episode. In the third stage, the participants who exceeded the cut-off point at test and retest were assessed more extensively, gathering information from various informers (parents and teachers) with diverse methods (interviews and rating scales).

The assessment procedure for both groups was approved by the Deontological Commission of the Association of Psychologists of Catalonia (COPC) and by the boards of directors of the schools that collaborated in the study, as well as by the teams of psychologists of the participating clinical centers. For the community sample, we obtained the parents' informed consent with a letter sent from the school director's office. The parents of the participants of the clinical sample gave their consent on the day of the initial interview and the children agreed to participate in the study.

Data was collected from the community sample anonymously and collectively, in groups of 20 students. This was carried out during the students' tutoring class by two psychologists in the presence of the classroom tutor. The participants indicated their sex and date of birth in the protocols and the questionnaires for the test and retest phases were paired for each classroom using these data.

The data of the clinical sample were collected by a clinical psychologist during the initial interview at the CYMHC. The CYMHC clinical team performed the diagnosis according to the DSM-IV-TR criteria (APA, 2000), disregarding the results of the RCDS.

The data presented herein are a part of a more extensive research that has assessed depressive symptomatology in childhood and adolescence. In this work, we only present the results obtained in the RCDS at the test and retest phases for the community sample and the test data for the

Table 2

Items that Load on each of the Five Factors of the RCDS, according to Reynold's (1989) Multifactor Model

\begin{tabular}{rl}
\hline & \multicolumn{1}{c}{ Five-Factor Model } \\
Factor & Items \\
\hline 11 & $3-7-8-15-16-19-21-22-28$ \\
2 & $4-6-9-12-13-14-20-29$ \\
3 & $2-11-18-24-26-27$ \\
4 & $1-5-17-30$ \\
5 & $10-23-25$ \\
\hline
\end{tabular}

clinical sample, in addition to the concurrent validity between the RCDS and the CDI.

\section{Data Analysis}

In order to confirm the factor structure proposed by Reynolds (1989), we analyzed two factor models with confirmatory factor analysis (CFA) using the EQS program, version 6.1 (Bentler \& $\mathrm{Wu}, 2002$ ). Given the nature of the items - Likert-type scale and biased distribution-we used the elliptic robust least square method (ERLS; Bentler \& Dijkstra, 1985) of parameter estimation. In both cases, the variance of the factors was fixed at 1 in order to provide the measuring scale; in the case of the five-factor structure, the analysis was carried out assuming that the factors were correlated. The first model assessed the possibility of a onedimensional structure, whereas the second proposal established the five factors proposed by Reynolds (1989). Table 2 displays the items of each factor.

To analyze the effect of the Grade $\times$ Sex interactions on the RCDS scores at the test and retest phase in the community sample, a repeated measures MANOVA was performed. Reliability was examined with Cronbach's alpha and test-retest reliability. For the clinical sample, the differences as a function of grade and sex were assessed by means of Kruskal-Wallis' $H$ and Mann-Witney's $U$.

\section{Results}

\section{Community Sample}

Table 3 displays the means and standard deviations of the RCDS at test and retest phases. The means obtained in the RCDS ranged between 46.47 and 49.03 (at test) and from 42.88 to 48.41 (at retest). Girls scored higher than boys in all grades, both at test and retest. Total retest scores were lower than test scores in all grades, for boys and girls, except for the scores of the $6^{\text {th }}$-grade girls, which were slightly higher at retest.

A mixed-factor analysis of variance, with one withingroup variable and two between-group variables, was conducted to identify the possible interactions between the two administration phases, participants' sex, and grade. The condition of equality of the variance-covariance matrixes was met: Box's $M: F(9.148447,9)=1.484, p=.147$. Table 4 shows the results of this analysis, with the value of the degrees of freedom corrected according to the missing/unrecorded values in each analysis.

As can be observed, there were no interactions between the administration phase of the instrument, grade, and sex, although there were significant differences between the administration phases, with the test scores being significantly higher than the retest scores, despite the fact that the effect size was not very high $\left(\eta^{2}=0.022\right)$. The between-subject effects showed that there were no significant differences for 
Table 3

Means and Standard Deviations (in Brackets) of the RCDS in the Community Sample, at Test and Retest, as a Function of Grade $\left(5^{\text {th }}\right.$ or $6^{\text {th }}$ of Primary Education) and Sex

\begin{tabular}{|c|c|c|c|c|c|c|c|c|c|c|c|c|c|c|c|c|c|c|}
\hline \multirow[b]{3}{*}{ Grade } & \multicolumn{9}{|c|}{ TEST } & \multicolumn{9}{|c|}{ RETEST } \\
\hline & \multicolumn{3}{|c|}{ Boys } & \multicolumn{3}{|c|}{ Girls } & \multicolumn{3}{|c|}{ Total } & \multicolumn{3}{|c|}{ Boys } & \multicolumn{3}{|c|}{ Girls } & \multicolumn{3}{|c|}{ Total } \\
\hline & $n$ & $M$ & $S D$ & $n$ & $M$ & $S D$ & $n$ & $M$ & $S D$ & $n$ & $M$ & $S D$ & $n$ & $M$ & $S D$ & $n$ & $M$ & $S D$ \\
\hline $5^{\text {th }}$ Grade & 57 & 46.47 & (11.03) & 67 & 49.0 & (11.24) & 124 & 47.85 & (11.17) & 32 & 42.88 & $(8.97)$ & 38 & 44.34 & (8.07) & 70 & 43.67 & $(8.46)$ \\
\hline $6^{\text {th }}$ Grade & 83 & 48.01 & $(9.88)$ & 108 & 48.3 & (10.13) & 191 & 48.19 & (10.00) & 56 & 45.84 & (10.90) & 74 & 48.41 & (11.79) & 130 & 47.29 & (11.44) \\
\hline
\end{tabular}

Table 4

Analysis of the Simple Effects and Interactions between Grade, Sex, and Administration Phase of the RCDS

\begin{tabular}{|c|c|c|c|c|c|}
\hline & $F$ & $d f$ & $p$ & Observed power & $\eta^{2}$ \\
\hline \multicolumn{6}{|l|}{ Within-subject contrasts } \\
\hline Retest & 4.332 & 1. 197 & .039 & .544 & .022 \\
\hline Retest $\times$ Sex & 0.043 & 1. 197 & .836 & .055 & \\
\hline Retest $\times$ Grade & 0.001 & 1. 197 & .975 & .050 & \\
\hline Retest $\times$ Sex $\times$ Grade & 3.395 & 1. 197 & .067 & .450 & \\
\hline \multicolumn{6}{|l|}{ Between-subject effects } \\
\hline Grade & 6.805 & 1. 197 & .010 & .738 & .033 \\
\hline Sex & 2.504 & 1. 197 & .115 & .350 & \\
\hline Grade $\times$ Sex & 0.195 & 1. 197 & .659 & .072 & \\
\hline
\end{tabular}

sex or for the Grade $\times$ Sex interaction, although there were significant differences for grade, with the $6^{\text {th }}$-graders scoring higher than the $5^{\text {th }}$-graders.

A main effect of course was observed in the differences between the scores of the $5^{\text {th }}$ - and $6^{\text {th }}$-graders. The mean total score of the $6^{\text {th }}$-grade participants was higher than that of the $5^{\text {th }}$-graders, although the effect size was moderate $\left(\eta^{2}\right.$ $=0.033)$ and did not indicate an intense effect.

\section{Confirmatory Factor Analysis}

We obtained the CFA estimations for two possible measurement solutions (five-factor model vs. one-factor model). The results of the ERLS estimations for the factor loadings yielded the fit indexes presented in Table 5 .

The analysis of the fit allowed us to improve the fit of the one-factor model slightly, compared to the five-factor

Table 5

Goodness-of-fit Indexes of the Two Measurement Models Proposed in the Community Sample

\begin{tabular}{lcr}
\hline Indexes & Five-Factor Model & One-Factor Model \\
\hline & 642.522 & 573.758 \\
$\chi^{2}$ & $d f=405$ & $d f=395$ \\
& $p<.001$ & $p .001$ \\
BBNFI & .688 & .721 \\
BBNNFI & .843 & .879 \\
CFI & .854 & .890 \\
IFI & .856 & .892 \\
RMR & .099 & .097 \\
SRMR & .116 & .117 \\
RMSEA & .100 & .088 \\
\end{tabular}

Note . BBNFI = Bentler-Bonett normed fit index, BBNNFI = Bentler-Bonett nonnormed fit index, CFI = comparative fit index, IFI = Bollen fit index, RMR = root mean square residual, $\mathrm{SRMR}=$ standardized root mean square residual, RMSEA $=$ Root mean square error of approximation, $\mathrm{CI}=90 \%$ confidence interval. 
model. Although neither solution offered an adequate result in the fit test (the values of $\chi 2$ were highly significant), the more global fit indexes were somewhat better in the onefactor model, especially the Bentler-Bonnet indexes and the values of the residual variance, in which the interval obtained in the one-factor model was better than that of the fivefactor model. The comparison of these two solutions was statistically significant. That is, the value of the TuckerLewis statistic (TLI) presented a value different from 0 $(p<.001)$, so that, although the fits were not entirely satisfactory for either of the two models, the evidence led us to choose the one-factor model (see Table 6).

\section{Reliability and Validity}

The one-dimensional solution was slightly more satisfactory for this sample; therefore, we provide the values of reliability and validity for this one-factor solution. Internal consistency (Cronbach's alpha) of the total scale was very good, both at test $(\alpha=.87,95 \%$ confidence interval $[\mathrm{CI}]$ between .82 and $.92)$, and at retest ( $\alpha=.89,95 \% \mathrm{CI}$ between .84 and .94$)$. testretest reliability was .66 (95\% CI between .62 and .71).

Concurrent validity of the RCDS with the CDI was assessed. The correlations between both instruments were high and equivalent both at test phase $(r=.767, p<.001$, 95\% CI between .71 and .81$)$ and at retest $(r=.771, p<$ $.001,95 \% \mathrm{CI}$ between .71 and .81 ).

\section{Clinical Sample}

Taking into account the results of the CFA of the community sample, we structured the results of the clinical sample using the one-factor solution. Table 7 displays the means and standard deviations of the RCDS according to sex and grade. The boys' means ranged between 47.64 and 58.25, and the girls' between 51.60 and 59.67.

The differences as a function of grade and sex were assessed by means of nonparametric statistics (KruskalWallis' $H$ and Mann-Witney's $U$ ). No statistically significant differences were found either for grade $(H=5.094, p=$ $.078)$ or for sex $(U=354, p=.119)$.

Reliability (Cronbach's alpha coefficient) of the RCDS was .90 (95\% CI between .87 and .93). The correlations between the scores of the RCDS and the CDI were 715 ( $p$ $<.001,95 \%$ CI between .66 and .76).

\section{Diagnostic Precision}

In order to examine the diagnostic precision of the instruments, we used sensitivity and specificity indexes. Sensitivity is the capacity of a test to identify positive cases; that is, the proportion of true positives. Specificity is the capacity to discriminate negative cases; the proportion of true negatives.

Sensitivity and specificity vary according to the cut-off points. In tests that assess psychopathological symptoms, such as Achenbach's (1991a, 1991b, 1991c) scales, the cutoff point is established at the $T$ score of 70 , or centile 98 , which corresponds to the mean plus two standard deviations. This interpretation method assumes that all scores equal to or higher than two standard deviations above the mean indicate the presence of clinically significant symptomatology.

In this work, we studied the diagnostic precision of the RCDS, understood as the ability to correctly classify the participants into clinically significant groups by means of the

Table 6

Tucker-Lewis Indexes for the Analysis of the Two Solutions in the Community Sample

\begin{tabular}{lcccc}
\hline & \multicolumn{4}{c}{ Hierarchical comparison of the models } \\
\cline { 2 - 5 } Models compared & TLI & $\Delta \chi^{2}$ & $\Delta d f$ & $p$ \\
\hline 1-factor model - 5-factor model & .228 & 68.764 & 10 & $<.001$ \\
\hline
\end{tabular}

Note. TLI $=$ Tucker-Lewis index.

Table 7

Means and Standard Deviations (in Brackets) of the RCDS Scores in the Clinical Sample as a Function of Grade (4 ${ }^{\text {th }}, 5^{\text {th }}$, or $6^{\text {th }}$ Grade of Primary Education)

\begin{tabular}{|c|c|c|c|c|c|c|c|c|c|}
\hline \multirow[b]{2}{*}{ Grade } & \multicolumn{3}{|c|}{ Boys } & \multicolumn{3}{|c|}{ Girls } & \multicolumn{3}{|c|}{ Total } \\
\hline & $n$ & $M$ & $S D$ & $n$ & $M$ & $S D$ & $N$ & $M$ & $S D$ \\
\hline $4^{\text {th }}$ Grade & 11 & 47.64 & (13.48) & 5 & 51.60 & (12.36) & 16 & 48.87 & (12.86) \\
\hline $5^{\text {th }}$ Grade & 12 & 58.25 & (11.49) & 6 & 59.67 & (20.19) & 18 & 58.72 & (14.35) \\
\hline $6^{\text {th }}$ Grade & 14 & 45.93 & $(8.93)$ & 14 & 57.14 & (16.07) & 28 & 51.54 & (13.98) \\
\hline TOTAL & 37 & 50.43 & (12.26) & 25 & 56.64 & (16.06) & 62 & 52.94 & (14.13) \\
\hline
\end{tabular}


receiver operating characteristics (ROC) curve. To perform this analysis, we used the group of 19 participants, diagnosed as depressed by the clinical teams of the CYMHCs, and the group of 45 nonsymptomatic participants. Figure 1 displays the area under the curve and Table 8 shows the values of sensitivity and specificity for the different cut-off points that may be useful, depending on whether one wishes to increase the sensitivity or the specificity when using the test. The area under the curve was .93 (95\% CI between .87 and .99$)$. The cut-off point that best combines the values of sensitivity and specificity was 61; sensitivity of 0.79 (95\% CI between .54 and .95) and specificity of 0.87 (95\% CI between .73 and .95 ).

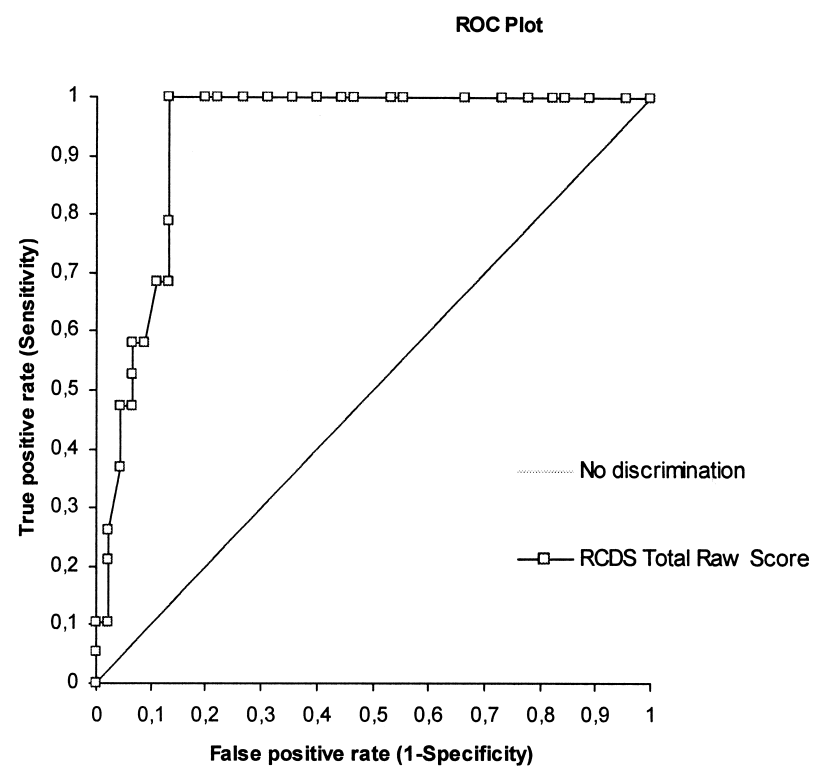

Figure 1. ROC curve. Area under the curve $=0.93$ (95\% confidence interval from 0.87 to 0.99 ).

\section{Conclusions}

In this work, we present the psychometric characteristics of the bilingual Spanish-Catalan version of the RCDS in two samples, a community sample and a clinical sample.

The factor structure models studied in the community sample did not yield an adequate degree of fit, although the one-factor solution presented a better fit than the multifactor (five-factor) solution. This improvement is not only present in the global fit (which was not high in any of the cases); however, in the one-factor solution, all the factor loadings were statistically significant, which did not occur in the fivefactor solution. Therefore, our results indicate that the RCDS is initially a one-dimensional test.

The reliability of the bilingual version of the RCDS, measured by means of the internal consistency and the testretest correlation, is satisfactory; the concurrent validity with the CDI is high, both for the community sample and the clinical sample. These results are congruent with those of other studies (Bartell \& Reynolds, 1986; Del Barrio et al., 1996; Reynolds, 1989; Reynolds \& Graves, 1989).

The distribution of the scores of the community sample confirms the tendency toward a decrease in the retest phase, the so-called "attenuation effect" (Egger \& Angold, 2004). Various investigations have shown that repeated administrations of self-reports are associated with a significant decrease in the scores at the second administration compared to the first (Finch, Saylor, Edwards, \& McIntosh, 1987; Kaslow, Rehm, \& Siegel, 1984; Meyer, Dyck, \& Petrinack, 1989). Moreover, the decrease of the scores at the retest phase in the community sample shows that the RCDS is sensitive to the temporal fluctuation that is common in depressive symptomatology, even with short intervals between administrations (Reynolds, 1989).

Table 8

Sensitivity and Specificity for Various Cut-off Points of the RCDS

\begin{tabular}{ccccc}
\hline Total RCDS Score (cut-off point) & Sensitivity & $95 \%$ CI & Specificity & $95 \%$ CI \\
\hline 59 & 1.00 & $0.82-1.00$ & 0.87 & $0.73-0.95$ \\
61 & 0.79 & $0.544-0.94$ & 0.87 & $66.3-92.1$ \\
62 & 0.68 & $0.43-0.87$ & 0.875 & $0.73-0.95$ \\
63 & 0.68 & $0.43-0.87$ & 0.90 & $0.76-0.96$ \\
67 & 0.58 & $0.34-0.80$ & 0.91 & $0.79-0.97$ \\
68 & 0.58 & $0.34-0.80$ & 0.93 & $0.82-0.99$ \\
69 & 0.53 & $0.29-0.76$ & 0.93 & $0.82-0.99$ \\
73 & 0.47 & $0.24-0.71$ & 0.96 & $0.82-0.99$ \\
74 & 0.47 & $0.24-0.71$ & 0.96 & $0.85-1.00$ \\
75 & 0.37 & $0.16-0.62$ & 0.98 & $0.85-1.00$ \\
77 & 0.26 & $0.09-0.51$ & 0.98 & $0.88-1.00$ \\
81 & 0.21 & $0.06-0.46$ & 0.98 & $0.88-1.00$ \\
86 & 0.11 & $0.01-0.33$ & 1.00 & $0.88-1.00$ \\
\end{tabular}

Note . $\mathrm{CI}=$ Confidence interval. 
The means and standard deviations obtained at the test and retest phases in the community and clinical samples are similar to those of other studies (Hepperlin, Stewart, \& Rey, 1990; Reynolds, 1989; Reynolds et al., 1985). No significant differences associated with sex were obtained, but significant differences were observed in grade, with scores increasing with age. These data confirm the tendency of no significant sex differences in the presence of depressive symptomatology before adolescence (Angold \& Rutter, 1992; NolenHoeksema \& Girgus, 1994).

Regarding the diagnostic utility of the RCDS, the cutoff point that best combines the indexes of sensitivity and specificity was 61 , lower than those presented by Reynolds (1989) and Del Barrio et al. (1996). The differences may be due to the estimation method of the cut-off point and the selection of the contrast groups. In the case of Del Barrio's Spanish sample, the cut-off point of 65 was estimated from the mean plus two standard deviations. If we apply this formula to the data of this work, the cut-off point would range between $68\left(6^{\text {th }}\right.$-graders $)$ and $71\left(5^{\text {th }}\right.$ graders), slightly higher than the one presented by Del Barrio et al (1996). The difference with the cut-off point presented by Reynolds could be related to the different method of forming the contrast groups. Reynolds used a group of 82 participants who were assigned either to the depressed group (10 participants) or to the nondepressed group (72 participants) on the basis of their scores in the Children's Depression Rating Scale Revised (Poznanski, Freeman, \& Mokros, 1985). In our work, the group of depressed participants had been diagnosed by the CYMHC clinical services, according to the criteria of the DSM-IVTR (APA, 2000), disregarding the RCDS scores, whereas the nonsymptomatic group comprised the participants who did not exceed the cut-off point established by Reynolds, both at test and retest.

Summing up, the bilingual Spanish-Catalan version of the RCDS presents adequate psychometric properties, so it can be considered a useful instrument to assess depressive symptomatology within our context. However, it should be taken into account that the data presented in this work were collected in the city of Barcelona and in its province, so that they should be used with the requisite caution with populations other than the ones assessed.

\section{References}

Abad, J., \& Amador, J. A. (1991). Teacher Report Form 4/18. Bilingual Spanish-Catalan edition. Unpublished manuscript. Facultat de Psicologia.Universitat de Barcelona.

Abad, J., \& Forns, M. (1991a). Child Behavior Checklist 4/18. Bilingual Spanish-Catalan edition. Unpublished manuscript. Facultat de Psicologia Universitat de Barcelona.

Abad, J., \& Forns, M. (1991b). Youth Self Report 11/18. Bilingual Spanish-Catalan edition. Universitat de Barcelona.
Achenbach, T. M. (1991a). Manual for the Child Behavior Checklist/4-18 and 1991 CBCL Profile. Burlington, VT: University of Vermont.

Achenbach, T. M. (1991b). Manual for the Teacher's Report Form and 1991 TRF Profile. Burlington, VT: University of Vermont.

Achenbach, T. M. (1991c). Manual for the Youth Self Report and 1991 YSR Profile. Burlington, VT: University of Vermont.

American Psychiatric Association (APA). (2000). Diagnostic and statistical manual of mental disorders ( $4^{\text {th }}$ ed., text revision). Washington, DC: Author.

Angold, A., \& Rutter, M. (1992). Effects of age and pubertal status on depression in a large clinical sample. Development and Psychopathology, 4, 5-28.

Baker, J. A., \& Reynolds, W. M. (1988, August). An examination of the benefits of training teachers to recognize depressed students in their classrooms. Paper presented at the $96^{\text {th }}$ Annual Convention of the American Psychological Association. Atlanta, GA.

Bartell, N. P., \& Reynolds, W. M. (1986). Depression and selfesteem in academically gifted and nongifted children: A comparison study. Journal of School Psychology, 24, 55-61.

Bentler, P., \& Dijkstra, T. (1985). Efficient estimation via linearization in structural models. In P. R. Krishnaiah (Ed.), Multivariate analysis, VI (pp. 9-42). Amsterdam: North-Holland.

Bentler, P.M., \& Wu, E.J.C. (2002). EQS 6 for Windows User's Guide. Encino, CA: Multivariate Software.

Brislin, R. W. (1986). The wording and translation of research instruments. In W. J. Lonner \& J. W. Berry (Eds.), Field methods in cross-cultural psychology. (pp. 137-164). Newbury Park, CA: Sage.

Brislin, R. W., Loner, W. J., \& Thorndike, R. M. (1973). Crosscultural research methods. New York: Wiley.

Candell, G. L., \& Hulin, C. L. (1987). Cross-language and crosscultural comparisons in scale translations. Journal of CrossCultural Psychology, 17, 417-440.

Coopersmith, S. (1981). Self-Esteem Inventory-Form B. Palo Alto, CA: Consulting Psychologists Press.

Del Barrio, V. (1990). Situación actual de la evaluación de la depresión infantil. Evaluación Psicológica / Psychological Assessment, 6, 171-209.

Del Barrio, V., Colondrón, M. F., De Pablo, C., \& Roa, M. L. (1996). Primera adaptación de las escalas de depresión de Reynolds RCDS y RADS a población española. RIDEP, 2, 75-100.

Egger, H. L. \& Angold, A. (2004). The Preschool Age Psychiatric Assessment (PAPA): A structured parent interview for diagnosing psychiatric disorders in preschool children. In R. Del Carmen-Wiggins \& A. Carter (Eds.), Handbook of infant, toddler, and preschool mental health assessment (pp. 223-243). New York: Oxford University Press.

Finch, A. J., Saylor, C. F., Edwards, G. L., \& McIntosh, J. A. (1987). Children's Depression Inventory: Reliability over repeated administrations. Journal of Consulting and Clinical Psychology, 16, 339-341.

Hepperlin, C. M., Stewart, G. W., \& Rey, J. M. (1990). Extraction of depression scores in adolescents from a general-purpose behaviour checklist. Journal of Affective Disorders, 18, 105-112. 
Hollingshead, A. B. (1975). Four-factor index of social status. Unpublished manual. New Haven, CT: Yale University.

Jané, M. C., Araneda, N., Valero, S. \& Domènech-LLaberia, E. (2000). Evaluación de la sintomatología depresiva del preescolar: correspondencia entre los informes de padres y de maestros. Psicothema, 12, 212-215.

Kaslow, N. P., Rehm, L. P., \& Siegel, A. W. (1984). Social-cognitive and cognitive correlates of depression in children. Journal of Abnormal Child Psychology, 12, 605-620.

Kazdin, A. E. (1981). Assessment techniques for childhood depression. Journal of the American Academy of Child Psychiatry, 20, 358-375.

Kazdin, A. E., \& Petti, T. A. (1982). Self-report and interview measures of childhood and adolescent depression. Journal of Child Psychology and Psychiatry, 23, 437-457.

Klein, D. N., Dougherty, L. R. \& Olino, T. M. (2005). Toward guidelines for evidence-based assessment of depression in children and adolescents. Journal of Clinical Child and Adolescent Psychiatry, 34, 412-432.

Kovacs, M. (1992). Manual of the Children's Depression Inventory. Toronto: Multi-Health Systems. [Spanish translation and adaptation: Del Barrio, V., \& Carrasco, M. A. CDI. Inventario de depresión infantil. Madrid: TEA Ediciones, 2004].

López, N. (1985). Assessing depressive symptoms using the Child Depression Scale and the Children's Depression Inventory: A cross cultural comparison of children in Puerto Rico and the United States. Unpublished doctoral dissertation. University of Wisconsin-Madison.

Mash, E. J. \& Hunsley, J. (2005). Evidence-based assessment of child and adolescent disorders: Issues and challenges. Journal of Clinical Child and Adolescent Psychology, 34, 362-379.

Meyer N. E., Dyck, D. G., \& Petrinack, R. J. (1989). Cognitive appraisal and attributional correlates of depressive symptoms in children. Journal of Abnormal Child Psychology, 17, 325336.

Nolen-Hoeksema, S., \& Girgus, J. S. (1994). The emergence of gender differences in depression during adolescence. Psychological Bulletin, 115, 424-443.

Orvaschel, H. (2004). Depressive disorders. In M. Hersen (Ed.), Psychological assessment in clinical practice: A pragmatic guide (pp. 297-319). New York: Brunner-Routledge.

Poznanski, E. O., Freeman, L. N., \& Mokros, H. B. (1985). Children's Depression Rating Scale - Revised. Psychological Bulletin, 21, 979-989
Rawson, H. E., \& Tabb, L. (1993). Effects of therapeutic intervention on childhood depression. Child and Adolescent Social Work Journal, 10, 39-52.

Reynolds, W. M. (1986). A model for screening and identification of depressed children and adolescents in school settings. Professional School Psychology, 1, 117-129.

Reynolds, W. M. (1987). Reynolds Adolescent Depression Scale. Professional manual. Odessa, FL: Psychological Assessment Resources.

Reynolds, W. M. (1989). Reynolds Child Depression Scale. Professional manual. Odessa, FL: Psychological Assessment Resources.

Reynolds, W. M. (2002). Reynolds Adolescent Depression Scale$2^{\text {nd }}$ Edition. Professional manual. Odessa, FL: Psychological Assessment Resources.

Reynolds, W. M., Anderson, G., \& Bartell, N. (1985). Measuring depression in children: A multimethod assessment investigation. Journal of Abnormal Child Psychology, 13, 513-526.

Reynolds, W. M., \& Graves, A. (1989). Reliability of children's reports of depressive symptomatology. Journal of Abnormal Child Psychology, 17, 647-655.

Shafii, M., \& Shafii, S. L. (1992). Dynamic Psychoterapy of Depression. In M. Shafii \& S. L. Shafii (Eds.), Clinical guide to depression in children and adolescents (pp. 157-176) Washington, DC: American Psychiatric Press. [Spanish translation: Psicoterapia dinámica de la depresión. In M. Shafii \& S. L. Shafii (Eds.), La depresión en niños y adolescentes. (pp.142-151) Barcelona: Martínez Roca, 1995].

Stark, K. D., Reynolds, W. M., \& Kaslow, N. J. (1987). A comparison of the relative efficacy of self-control therapy and behavioral problem-solving therapy for depression in children. Journal of Abnormal Child Psychology, 15, 91-113.

Tisher, M., \& Lang, M. (1978). Children's Depression Scale: Research Edition. Melbourne: The Australian Council for Educational Research. [Spanish translation: Cuestionario de Depresión para Niños. Madrid: TEA, 1983]

World Health Organization (WHO). (1992). The ICD-10 Classification of mental and behavioural disorders. Clinical descriptions and diagnostic guidelines (10th revision) (CIE10). Geneva: Author.

Received December 29, 2006 Revision received December 30, 2007 Accepted January 22, 2008 